\title{
Letramento digital na EJA: integrando Cultura Digital, Língua Portuguesa e Lite ratura
}

\author{
Juça ra Benvenuti ${ }^{1}$, Clevi Elena Rapkie wicz ${ }^{1}$ \\ ${ }^{1}$ Colégio de Aplicação -Universidade Federal do Rio Grande do Sul \\ (UFRGS) - Porto Alegre - RS - Brasil \\ benvenutieufrgs.br, clevi.capufrgsegmail.com
}

\begin{abstract}
This article presents the work accomplished through the integration of Digital Culture, Portuguese Language and Literature with EJA students. The pedagogical actions united the themes of education and work to expand the vision that students already bring with them when they arrive at school. This proposal came after the study that pointed out that literacy is far beyond literacy, due to the social implications of the use of reading and writing (Magda Soares), which can also anticipate that the digital literacy process is beyond digital inclusion Social use of information and communication technologies (ICT). A dynamic and varied methodology ensured results that indicate advances in the way of thinking in networks, development of authorship, besides the increase in digital literacy with the appropriation of different tools and resources.
\end{abstract}

Key-words: digital literacy, EJA, work

Resumo. Este artigo apresenta o trabalho realizado por meio da integração entre Cultura Digital, Lingua Portuguesa e Literatura com alunos de EJA. As ações pedagógicas uniram os temas educação e trabalho para expandir a visão que os alunos já trazem consigo ao chegar à escola. Esta proposta surgiu após o estudo que apontou que o letramento está muito além da alfabetização, devido às implicações sociais do uso da leitura e da escrita (Magda Soares), o qual pode também antecipar que o processo de letramento digital está além da inclusão digital ao preconizar o uso social das tecnologias de informação e comunicação (TIC). Uma metodologia dinâmica e variada garantiu resultados que apontam avanço no modo de raciocinar em rede, desenvolvimento da autoria, além do aumento no letramento digital com apropriação de diferentes ferramentas e recursos.

Palavras-chave: letramento digital, EJA, trabalho

\section{Introdução: contextualização e fundamentação teórica}

Este trabalho está situado na fronteira entre o ensino de graduação e de educação básica, pois integra estudantes desses dois níveis, sob orientação de professoras de Língua Portuguesa e de Cultura Digital. O projeto foi desenvolvido em uma turma de EJA, visando associar um conjunto de atividades de Língua Portuguesa e Literatura com Cultura Digital, com apoio de Licenciandos em Letras da UFRGS atuando como bolsistas de Iniciação C ientífica. 
VI Congresso Brasileiro de Informática na Educação (CBIE 2017)

Anais do XXIII Workshop de Informática na Escola (WIE 2017)

A proposta de trabalhar de forma integrada ocorreu pela constatação que o letramento está muito além da alfabetização, devido às implicações sociais do uso da leitura e da escrita (SOARES, 2010), o qual pode também antecipar que o processo de letramento digital está além da inclusão digital ao preconizar o uso social das tecnologias de informação e comunicação (TIC).

Uma vez que as TIC (particularmente a Internet) mudaram nosso modo de viver e estar no mundo; também nosso modo de trabalhar mudou. A importância do mundo do trabalho para esse público (alunos de Educação de Jovens e Adultos - EJA) é sustentada por uma visão freireana de que a educação popular não pode dissociar-se da realidade do aluno sob pena de não atingi-lo ou não gerar conhecimento.

Segundo Benvenuti (2012, p. 18) "essa educação caracteriza-se por ser um encontro entre interlocutores, educador e educando, que procuram na busca do conhecimento a significação da realidade e, através da prática, buscam o poder de transformação do próprio homem e, por consequência, da sociedade"

Freire ainda coloca que professores e alunos estão em posições equivalentes de fazeres na sala de aula, destacando um capítulo intitulado "Não há docência sem discência”! de seu livro Pedagogia da Autonomia: saberes necessários à prática educativa, para este tema.

Assim, alunos de escola pública, provenientes de realidade muito distintas, constituindo classes heterogêneas, como é o caso dos jovens e adultos, demandam olhares e planejamentos especiais. O público de EJA constituído em sua grande maioria por trabalhadores já chega à escola com muitos saberes acumulados, os quais foram sendo adquiridos sem nenhuma sistematização ou organização, como a escolar. Esse fator leva estes alunos a um estranhamento na hora de estudar conforme os moldes compartimentados da educação brasileira.

O Indicador de Alfabetismo Funcional (INAF) no Brasil aponta algumas pesquisas as quais indicam que pessoas com baixa ou nenhuma escolaridade apresentaram alto desempenho nos testes realizados, enquanto que outras com alta escolaridade, nível superior completo e incompleto, não se saíram bem. Soares (2003) pensa que uma hipótese seria porque a escola realiza atividades de leitura e escrita desvinculadas do contexto social.

Já que o letramento não ocorre apenas no período da alfabetização ou na escola, ele se estende por toda a vida da pessoa e de acordo com as práticas sociais que os indivíduos têm, pode ir mudando, é natural esperar que os estudantes de EJA tenham desenvolvido algumas áreas do conhecimento e outras não.

Em seu livro Benvenuti (2012) destaca o trabalho de dois estudiosos Shirley Brice Heath e Brian Street, os quais cunharam os termos eventos e práticas de letramento. O primeiro se refere a "qualquer ocasião em que a escrita é parte integrante da natureza das interações entre os participantes e de seus processos interpretativos", enquanto o segundo refere-se a uma "concepção cultural mais ampla de formas particulares de pensar e ler e de escrever em contextos culturais e incluem os modelos sociais de letramento utilizados pelos participantes e os significados atribuidos a esses eventos de letramento".

Em uma sociedade permeada pelas TIC como a Sociedade da Informação, o cidadão encontra-se, necessariamente, em alguma medida, e em alguns contextos, 
incluído. Neste sentido, é preciso a visão de inclusão digital focando em um processo de letramento uma vez que, como aponta Soares (2010) o letramento é um estado, um continuum, pois ao longo da vida o uso da escrita e da leitura em nosso cotidiano vão se alterando. Assim também ocorre com o uso das TIC. Por isso não faz sentido falar de uma oposição binária entre letrado e iletrado, mas sim de gradações de letramento que dependem do contexto social, cultural e histórico deste indivíduo (WARSCHAUER, 2006).

Uma vez que o letramento refere-se a práticas sociais, deve-se focar em ações que visem à "promoção do processo de inclusão social e não à superação da exclusão digital" (PASSERINO, MONTARDO, 2007). Isto porque as habilidades e competências necessárias para a inclusão variam ao longo do tempo e de acordo com o público alvo. No caso deste projeto, viu-se potencial para integrar Cultura Digital e Língua Portuguesa e Literatura para buscar atingir metas de aquisição/aumento do letramento digital relacionado com o mundo do trabalho de forma interdisciplinar, mostrando aos alunos novos horizontes de algo que já faz parte de suas vidas. Há que se observar que, em pesquisa bibliográfica realizada nos anais do SBIE e WIE dos últimos cinco anos não foi localizado relato de ação ou reflexão acerca de letramento digital voltado para EJA.

\section{A metodologia inclusiva}

Nas aulas de Língua Portuguesa e Literatura de cada nível da EJA são adotadas temáticas norteadoras das atividades, as quais foram desenvolvidas a partir de uma pesquisa minuciosa realizada em uma tese de doutoramento (BENVENUTI, 2012). Assim, no primeiro ano do ensino a temática é Identidade, no segundo ano a temática é O Mundo do Trabalho, e no $3^{\circ}$ ano o tema é Comunidades.

O projeto aqui relatado foi desenvolvido com alunos do segundo ano do ensino médio, portanto todas as produções estão relacionadas à temática norteadora, que desta forma busca garantir, além da permanência dos alunos de EJA na escola (tenta-se evitar o máximo possível a evasão escolar, seja por desmotivação ou por distanciamento da sua realidade com a realidade escolar), também se busca alavancar a qualidade de vida no trabalho destes cidadãos. Cumpre destacar que a evasão escolar, que é um dos fenômenos recorrentes na EJA, juntamente com a repetência sucessiva e dificuldades de aprendizagem de diferentes ordens, caracterizam o fracasso escolar atribuído aos próprios alunos, isentando o sistema de ensino da responsabilidade de buscar alternativas para solução.

Para facilitar o entendimento do trabalho que foi desenvolvido, apresentamos um breve relato metodológico, pois foi adotada uma sequência de ações pedagógicas integrando Cultura Digital (CD), Língua Portuguesa e Literatura (LP). Como primeira atividade os alunos assistiram na escola ao filme "Um senhor estagiário", dirigido por Nancy Meyers. A escolha recaiu neste filme porque traz no enredo um senhor aposentado que volta a trabalhar, precisando se adaptar - o que nesse sentido significa letramento digital - a uma loja de serviços online, em que os desafios aparecem desde o início: a entrevista precisa ser gravada em vídeo. Após o filme, foi realizado um debate sobre as questões que envolviam alguns aspectos da história, evidenciando o uso da internet no trabalho, não apenas no lazer ou nas relações sociais, como é o uso predominante geralmente por falta de conhecimento dos alunos. 
Paralelamente a esta ação de Cultura Digital, na aula de Língua Portuguesa e Literatura os alunos leram, discutiram e anotaram passagens do texto "O Anúncio" de Olavo Bilac, no qual um sítio é anunciado para venda de forma tão primorosa que o dono desiste de vendê-lo ${ }^{1}$. Após realizar a interpretação do texto, foi apresentada e trabalhada em aula uma proposta sobre anúncios classificados e não classificados, veiculados em diversas mídias. Também os anúncios de emprego impressos e online foram abordados, para ficar evidente que, com a evolução tecnológica e o uso das TIC, o modo de criar, divulgar e interagir com anúncios foi trans formado.

Em aula subsequente, os alunos foram levados ao laboratório de informática da escola para acessar anúncios de emprego em sites como "Infojobs" e "Casaecafé". A atividade consistia em realizar uma pesquisa nos sites, detectar um anúncio que correspondesse às expectativas individuais, selecionar o texto e responder na forma de e-mail. No caso de não haver correspondência ou interesse por parte do aluno, a instrução previa uma resposta fictícia que funcionaria apenas como exercício para um futuro uso do recurso. A mensagem de resposta deveria ter os elementos necessários à identificação do candidato, as características que o qualificavam para a vaga e atender aos itens solicitados pelo proponente, tudo devidamente explicado durante a realização da atividade pelas professoras e bolsistas de apoio. Cumpre destacar que a elaboração de respostas online não é uma prática cotidiana dos alunos da EJA, mas é uma demanda do mercado de trabalho.

A ação seguinte foi uma produção imagético-textual, desenvolvida em diversas etapas assim constituídas: inicialmente nas aulas de Língua Portuguesa e Literatura foram realizados estudos sobre as histórias em quadrinhos, incluindo todos os elementos presentes em uma narrativa, como personagens, tempo, espaço, enredo. Além disso, destacou-se a presença do narrador, dos diálogos através do uso dos balões e das legendas. Também foram enfocados os aspectos ligados à linguagem como uso de onomatopeias e interjeições próprias deste gênero textual. Para propiciar contato com diferentes mídias, iniciou-se com os alunos manuseando revistas de quadrinhos impressas, leram na sala, recortaram, fizeram a produção de seu próprio material de apo io para consulta, com as informações do estudo dirigido.

De posse destas informações os alunos foram instruídos a criar um roteiro para produzir sua própria história em quadrinhos a ser transportada para o mundo virtual através da ferramenta Pixton, mantendo a temática do Mundo do Trabalho como norteadora. A ferramenta Pixton foi escolhida com base nos critérios apontados em Santos, Rapkiewicz e Santos (2014). Uma aula específica foi desenvolvida para explorar o uso dos recursos do Pixton e na aula seguinte ocorreu a produção das HQ no

\footnotetext{
1 "O dono de um pequeno comércio, a migo do grande poeta Olavo Bilac, abordou -o na rua:

- Sr. Bilac, estou precisando vender meu sítio, que o Senhor tão bem conhece. Poderá redigir o anúncio para o jornal?

Olavo Bilac apanhou o papel e escreveu:

"Vende-se encantadora propriedade, onde cantam os pássaros ao amanhecer no extenso arvoredo, cortada por cristalinas e marejantes águas de um ribeiro. A casa, banhada pelo sol nascente, oferece a sombra tranquila das tardes, na varanda".

Meses depois, topa a poeta com o ho meme pergunta-lhe se havia vendido o sítio.

- "Nem pense nisso, disse o homem! Quando li o anúncio, é que percebi a maravilha que tinha". BILAC, Olavo. O anúncio. Apud Benvenuti, Juçara. Letramento, Leitura e Literatura no Ensino Médio da Modalidade de Educação de Jovens e Adultos: uma proposta curricular. Tese (Doutorado). UFRGS, 2012.
} 
computador desktop no laboratório de informática da escola. Alguns alunos, ainda que poucos, preferiram fazer uso do serviço em seu próprio celular.

As atividades subsequentes, todas perpassadas pela integração com TIC, realizadas com a turma, mantiveram a temática do Mundo do Trabalho, buscando sempre a inserção do jovem aluno-trabalhador e qualificando as condições dos mais velhos. Assim, uma ação desenvolvida foi a produção de currículo. A tarefa de cunho individual foi desenvolvida em etapas, isto é, inicialmente os alunos receberam orientações de redação em aulas de Língua Portuguesa e posteriormente receberam instruções acerca dos recursos tecnológicos disponíveis para qualificação de seu material, bem como a própria digitação, formatação adequadas e os meios de envio. Também foi realizada a elaboração de cartas de apresentação que acompanharam os currículos.

Outra ação desenvolvida e que foi complementar a esta atividade foi a orientação para entrevistas de emprego, incluindo recomendações de comportamento, de vestimenta, abordagens de temáticas durante a conversa com o entrevistador. A ação foi mediada pela visualização de vídeos, discussão e simulação de situações possíveis.

Estas atividades foram desenvolvidas durante três semestres. No primeiro semestre não houve coletada de dado sistemática, sendo anotados os pontos falhos do projeto durante o transcorrer do mesmo e adaptado para os dois semestres seguintes, e no final dos quais, foram coletados dados para análise e comparação. A seguir, apresentamos alguns resultados.

\section{Alguns resultados}

A coleta de dados foi realizada através de um questionário respondido por escrito pelos alunos em um dos últimos encontros do semestre. No final do segundo semestre do projeto, vinte e dois alunos completaram as informações do instrumento, o que corresponde a um número um pouco menor do que o total de alunos da turma, porque alguns haviam faltado à aula e não houve outra data para nova coleta das informações. As questões que nortearam a pesquisa giraram em torno das atividades desenvolvidas ao longo do semestre e as alternativas objetivas ofereciam quatro opções de respostas: "Concordo plenamente", "Concordo", "Não concordo, nem discordo" e "Discordo".

As perguntas foram as seguintes:

1. As aulas de Língua Portuguesa integradas às da Cultura Digital ajudaram a desenvolver meus conhecimentos nas duas áreas?

2. A atividade de enviar um e-mail me candidatando a uma vaga de trabalho foi relevante para minha vida?

3. Foi importante conhecer sites de vaga de emprego (infojobs, casa\&café)?

4. Assistir ao filme "Um Senhor Estagiário" me mostrou que a vida pessoale profissional está cada vez mais conectada ao mundo virtual?

5. Foi relevante fazer uma HQ sobre "O Mundo do Trabalho" usando o Pixton?

6. Considero importante a montagem do currículo realizada em conjunto com as duas disciplinas?

7. O material lido e discutido em aula sobre entrevistas de emprego será útil para mim?

8. Acho importante saber usar o computador e a internet para o desempenho de funções no trabalho? 
VI Congresso Brasileiro de Informática na Educação (CBIE 2017)

Anais do XXIII Workshop de Informática na Escola (WIE 2017)

9. Penso que é importante saber usar o computador e a internet para realizar tarefas da escola?

10. Eu costumo usar a internet para trabalhar, estudar e procurar emprego?

11. As atividades desenvolvidas me motivaram a procurar mais coisas sobre o mundo do trabalho que a internet pode oferecer, como: ofertas de emprego, cursos, capacitações, ferramentas para realização de algum trabalho, etc.?

12. As atividades envolvendo "O Mundo do Trabalho" nesse semestre contribuíram muito para minha vida pessoal ou profissional?

As respostas dos alunos foram tabuladas incluindo as duas primeiras opções ("Concordo plenamente" e "Concordo") e ("Não concordo, nem discordo" e "Discordo") traduzidas em percentua is para visualização do conjunto:

Tabela 1. Respostas ao questionário ao final do segundo semestre

\begin{tabular}{|c|c|c|c|c|c|c|}
\hline Ques tões & $\begin{array}{c}\text { Concordo } \\
\text { ple namente }\end{array}$ & Concordo & $\%$ & $\begin{array}{c}\text { Não } \\
\text { concordo, } \\
\text { nem } \\
\text { discordo }\end{array}$ & Dis cordo & \% \\
\hline 1 & 13 & 9 & $100 \%$ & 0 & 0 & $0 \%$ \\
\hline 2 & 11 & 7 & $81 \%$ & 3 & 1 & $18 \%$ \\
\hline 3 & 14 & 4 & $81 \%$ & 4 & 0 & $18 \%$ \\
\hline 4 & 8 & 12 & $90 \%$ & 2 & 0 & $9 \%$ \\
\hline 5 & 8 & 9 & $77 \%$ & 5 & 0 & $22 \%$ \\
\hline 6 & 13 & 7 & $90 \%$ & 1 & 1 & $9 \%$ \\
\hline 7 & 15 & 5 & $90 \%$ & 1 & 1 & $9 \%$ \\
\hline 8 & 18 & 4 & $100 \%$ & 0 & 0 & $0 \%$ \\
\hline 9 & 17 & 5 & $100 \%$ & 0 & 0 & $0 \%$ \\
\hline 10 & 12 & 8 & $90 \%$ & 2 & 0 & $9 \%$ \\
\hline 11 & 13 & 8 & $95 \%$ & 0 & 1 & $4 \%$ \\
\hline 12 & 12 & 7 & $86 \%$ & 2 & 1 & $13 \%$ \\
\hline
\end{tabular}

No final do terceiro semestre do projeto, quatorze alunos responderam ao questionário com treze questões, uma a mais do que anteriormente. Isto ocorreu porque foi introduzida uma atividade no programa do semestre: a confecção de uma carta de apresentação do currículo para ser enviada junto com o CV. Assim, para cada uma das atividades corresponde uma pergunta o que permite avaliar o trabalho desenvolvido. A pergunta acrescentada tomou a posição de número 6 na listagem das perguntas e foi a seguinte: "Fazer a carta de apresentação valorizou o meu currículo?" 
VI Congresso Brasileiro de Informática na Educação (CBIE 2017)

Anais do XXIII Workshop de Informática na Escola (WIE 2017)

Tabela 2. Respostas ao questionário ao final do terceiro semestre

\begin{tabular}{|c|c|c|c|c|c|c|}
\hline Ques tões & $\begin{array}{c}\text { Concordo } \\
\text { plenamente }\end{array}$ & Concordo & $\%$ & $\begin{array}{c}\text { Não } \\
\text { concordo, } \\
\text { ne m } \\
\text { discordo }\end{array}$ & Dis cordo & \% \\
\hline 1 & 7 & 7 & $100 \%$ & 0 & 0 & $0 \%$ \\
\hline 2 & 3 & 6 & $64,3 \%$ & 3 & 2 & $35,7 \%$ \\
\hline 3 & 4 & 7 & $78,5 \%$ & 3 & 0 & $21,5 \%$ \\
\hline 4 & 4 & 6 & $90,9 \%$ & 1 & 0 & $9,1 \%$ \\
\hline 5 & 4 & 8 & $85,7 \%$ & 2 & 0 & $14,2 \%$ \\
\hline 6 & 4 & 7 & $78,5 \%$ & 2 & 1 & $21,5 \%$ \\
\hline 7 & 7 & 5 & $85,7 \%$ & 2 & 0 & $14,2 \%$ \\
\hline 8 & 4 & 6 & $71,4 \%$ & 4 & 0 & $28,5 \%$ \\
\hline 9 & 6 & 7 & $100 \%$ & 0 & 0 & $0 \%$ \\
\hline 10 & 7 & 6 & $92,8 \%$ & 1 & 0 & $7,1 \%$ \\
\hline 11 & 5 & 7 & $85,7 \%$ & 2 & 0 & $14,2 \%$ \\
\hline 12 & 4 & 8 & $85,7 \%$ & 2 & 0 & $14,2 \%$ \\
\hline 13 & & $98,5 \%$ & 2 & 1 & $21,5 \%$ \\
\hline
\end{tabular}

Deves-se atentar, quanto à pergunta 4, que tivemos três alunos que não responderam, porque não estavam presentes à aula em que foi passado o filme e não conseguiram assistir por conta própria. E quanto à questão 9, um aluno deixou em branco. As percentagens foram calculadas dentro da proporcionalidade.

Na Figura 1 destacamos as perguntas 4 (assistir filme) e 5 (produção de HQ) mostrando que houve, nos dois semestres (turmas diferentes) boa aceitação tanto de atividades de leitura em outra mídia (assistir filme) quanto de autoria (produzir tirinha).

Pergunta 4 - Assis tir filme

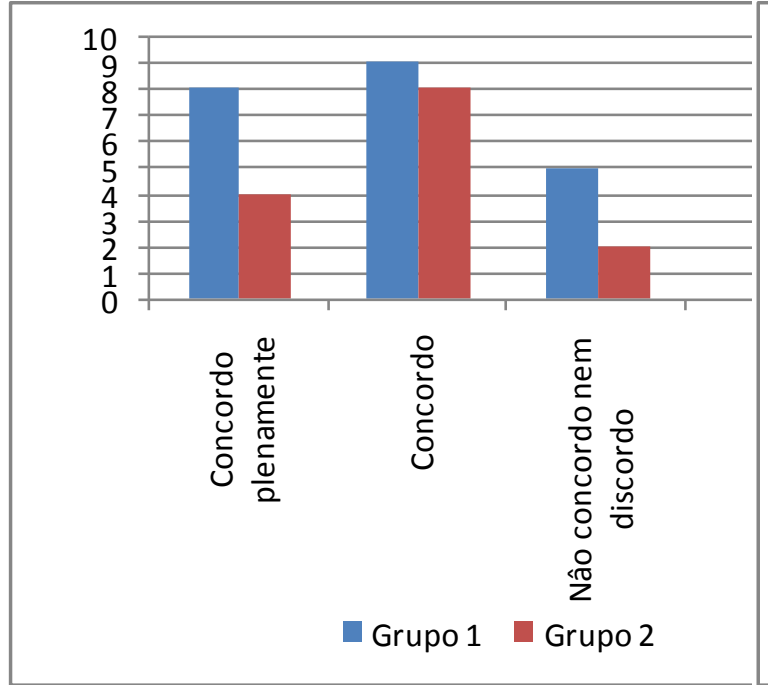

Pergunta 5 - Produzir HQ

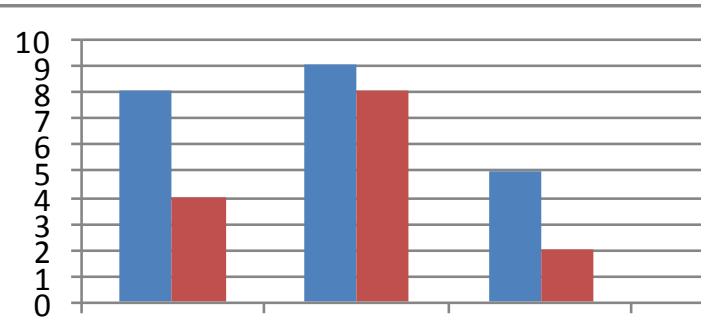

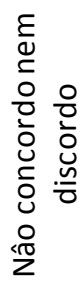

Grupo 1 Grupo 2

Figura 1. Comparando os grupos - Assistir filme e produzir tirinha 
VI Congresso Brasileiro de Informática na Educação (CBIE 2017)

Anais do XXIII Workshop de Informática na Escola (WIE 2017)

Além das questões objetivas também foi incluída uma pergunta subjetiva para que os alunos manifestassem livremente suas opiniões pessoais sobre as atividades desenvolvidas ou sobre algum ponto que desejassem colocar mais ideias.

Muitos alunos da EJA não respondem a questão aberta, mas as respostas presentes permitiram construir a nuvem da Figura 2 através do serviço online Voyant Tools, disponível em https://voyant-tools.org/

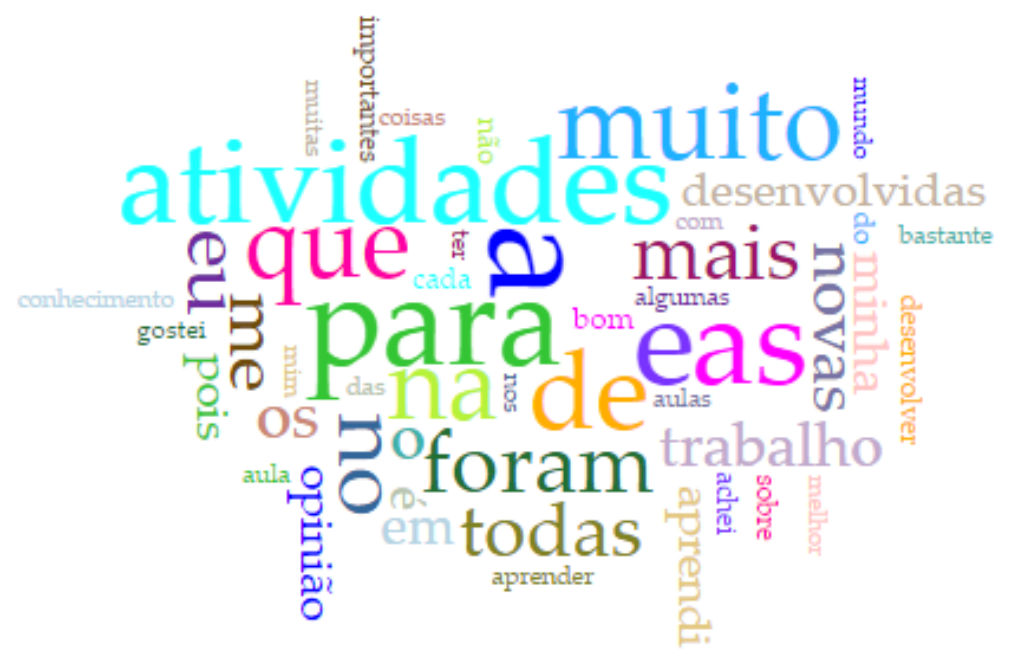

Figura 2 - Pe rcepção de dis criminação linguística

O tamanho das palavras, na nuvem, é proporcional a frequência com que foram citadas nas respostas dos alunos. Observa-se que há predominância de termos que introduzem a resposta, como opinião, atividades, desenvolvidas, propiciando oportunidade de se manifestarem através de sentenças completas.

Entre as respostas, verifica-se que há destaque a integração dos componentes curriculares e da busca do domínio de TIC para o mundo do trabalho:

"Gostei de todas [atividades], principalmente as que envolveram Cultura Digital, pois, hoje em dia, precisamos da Internet para quase tudo!"

"Para mim as aulas desenvolvidas foram muito importantes, pois contribuíram para ter mais conhecimento sobre tecnologia e mundo do trabalho."

"Me ajudou a tirar muitas dúvidas e a desenvolver novas técnicas no PC, a Língua Portuguesa a desenvolver a escrita."

"Para mim essas atividades foram muito boas, aprendi a me situar mais com procura de trabalho, e mexer melhor em sites no computador."

' $\mathrm{Na}$ minha opinião, as atividades propostas, nesse semestre, foram importantes, pois nos auxiliam a nos candidatarmos a uma vaga no mercado de trabalho, que está cada vez mais concorrido." 
"Achei muito importante e divertido ter informática, pois aprendi técnicas que eu não sabia. Ainda tenho dificuldades, mas aos poucos, na prática, vou aprendendo.

'Na minha opinião eu gostei bastante de cada atividade, passei a entender a ferramenta do Pixton. Na leitura com os colegas, na opinião de cada um aprendi a valorizar os compromissos de fazer as tarefas, gostei muito de aprender novas atividades."

Foi possível também a manifestação contrária as atividades, sobretudo mostrando uma visão mais instrumental do uso das TIC com certa desvalorização de propostas que saiam do 'be-a-bá' da micro-informática. É o caso da atividade com HQ:

"Achei as atividades estimulantes e necessárias, em alguns momentos foram enfadonhas. Outras, como a dos quadrinhos, me confund iram."

'Na minha opinião é que certa coisa tipo o HQ não é muito útil para vida pessoal. No lugar podia ser uma ajuda no EXCEL e WORD."

No caso dessas duas falas, percebe-se que não foi possível levar os alunos a ultrapassar a visão de inclusão digital para terem uma visão de letramento, na qual não se busca "adequar sujeitos supostamente passivos ou determinados pelo sistema às novas demandas do capitalismo globalizado", mas sim "compreender e fomentar os modos pelos quais os sujeitos podem usar as TIC para definir e implementar suas próprias demandas (éticas, políticas, culturais, etc.)", apropriando-se desta tecnologia (BUZATO, 2009, p. 34).

\section{Algumas considerações finais}

As atividades integradas entre Cultura Digital e Língua Portuguesa visam, ao mesmo tempo, o letramento e o letramento digital, na medida em que propiciam oportunidade aos alunos tanto de leitura quanto de escrita manual e digital usando diferentes recursos desde aplicativo como editor de texto para editar um currículo até respostas a anúncios online. Não se busca, nesse projeto, a mera instrumentalização dos alunos dominando um ou outro aparato tecnológico dissociado de sua realidade cotidiana. E, certamente, a realidade cotidiana de alunos adultos na modalidade EJA está permeada de situações relativas a busca de emprego, melhoria de emprego e permanência nesse.

As respostas abertas dadas pelos alunos denotam em poucos casos a não compreensão da proposta, mas ainda assim implica em repensar a forma de comunicação de algumas atividades como o uso de história em quadrinhos buscando maior valorização da mesma. Entre as sugestões para isso dadas pelos próprios alunos está o contato com pessoas que, no mundo do trabalho, ganhem seu sustento em atividade relacionadas com tirinhas ou histórias em quadrinhos.

Entre as dificuldades encontradas nesse projeto apontamos a infraestrutura muitas vezes precária do laboratório de informática e do acesso a rede em uma escola pública. Também, uma característica da modalidade EJA que é a evasão e as faltas constantes as aulas, dificultando o desenvolvimento de propostas contínuas como desse projeto. 
VI Congresso Brasileiro de Informática na Educação (CBIE 2017)

Anais do XXIII Workshop de Informática na Escola (WIE 2017)

Vislumbra-se a continuidade desse estudo na proposição da ampliação do uso do celular, na medida em que se observa, cada vez mais, alunos que manipulam bem este recurso, mas têm extrema dificuldade de manuseio de computadores.

\section{Referências}

BENVENUTI, Juçara. O dueto leitura e literatura na Educação de Jovens e Adultos. Porto Alegre: Mediação, 2012.

BUZATO, Marcelo El Khouri. Letrame nto e inclusão: do estadonação à era das TIC. DELTA, São Paulo, v. 25, n. 1, 2009.

HEATH, Shirley Brice. "Protean Shapes in Literacy Events: Ever-Shifting Oral and Literate Traditions". In: Tannen, D. (edl.) Spoken and written language: exploring ora lity and lite racy. Norwood (N.J.): Ablex,. p. 91-117, 1982.

PASSERINO, L. M. MONTARDO, S. P. . Inclusão social via acessibilidade digital: proposta de inclusão digital para Pessoas com Necessidades Especiais (PNE). ECompós (Brasília), v. 8, p. 118, 2007.

SANTOS, Thessiê; RAPKIEWICZ, Clevi; SANTOS, Victor. Análise de serviços online para produção de histórias em quadrinhos. TISE, p. 674-677, 2014. Disponível em $<$ http://www.tise.c1/volumen10/TISE2014/tise2014 submission 206.pdf >. Acesso em 20 junho 2017.

SOARES, Magda. Letramento: um tema em três gêneros. $4^{\mathrm{a}}$ Ed., Belo Horizonte: Autêntica Editora, 2010

Letramento e escolarização. In: RIBEIRO, Vera Masagão. Letramento no Brasil. São Paulo: Global, 2003. p. 89-113.

STREET, Brian V. (1984). Lite racy in Theory and Practice. Cambridge: Cambridge University Press.

WARSCHAUER, Mark. Tecnologia e Inclusão Social: a exclusão digital em debate. São Paulo: Editora SENAC, 2006 